\title{
A study of Contaminate diffusion Through Layered Soil due to leachate migration From Landfill Site
}

\author{
A. A. AL-Daood \\ Assistant lecture \\ Technical Institute of Mosul
}

\begin{abstract}
Contamination of soils and groundwater is considered as one of the major environmental problems. So, water and contaminate movement through soil especially in layered soil should be studied thoroughly. This research aims to study the contamination movement in a layered soil considering; water table fluctuation and applying the theories of transfer and diffusion in the unsaturated case. Numerical model with GEOSLOP software was used for simulating the movement of the contaminant through both saturated and unsaturated layered soils.

The study shows that various physical properties of soil layers has a serious impact on the movement of the contaminants, also it shows that the order of layers has a effective role in the extent of the movement and concentration of leachate in the area surrounding the location of landfills in the case of unsaturated soil, while changes in the level of groundwater don't make any change that can be mentioned with the number and order of layers but leads to a small changes in concentration of leachate. Whereas steady saturated soil conditions did not affect by the order and number of layers on the movement of leachate, but it is effected by the change in ground water level, the change including the concentration and extend of the contaminate movement.
\end{abstract}

Keywords: Contaminant, finite element, unsaturated soil, diffusion, multilayer soils, GEO-SLOPE.

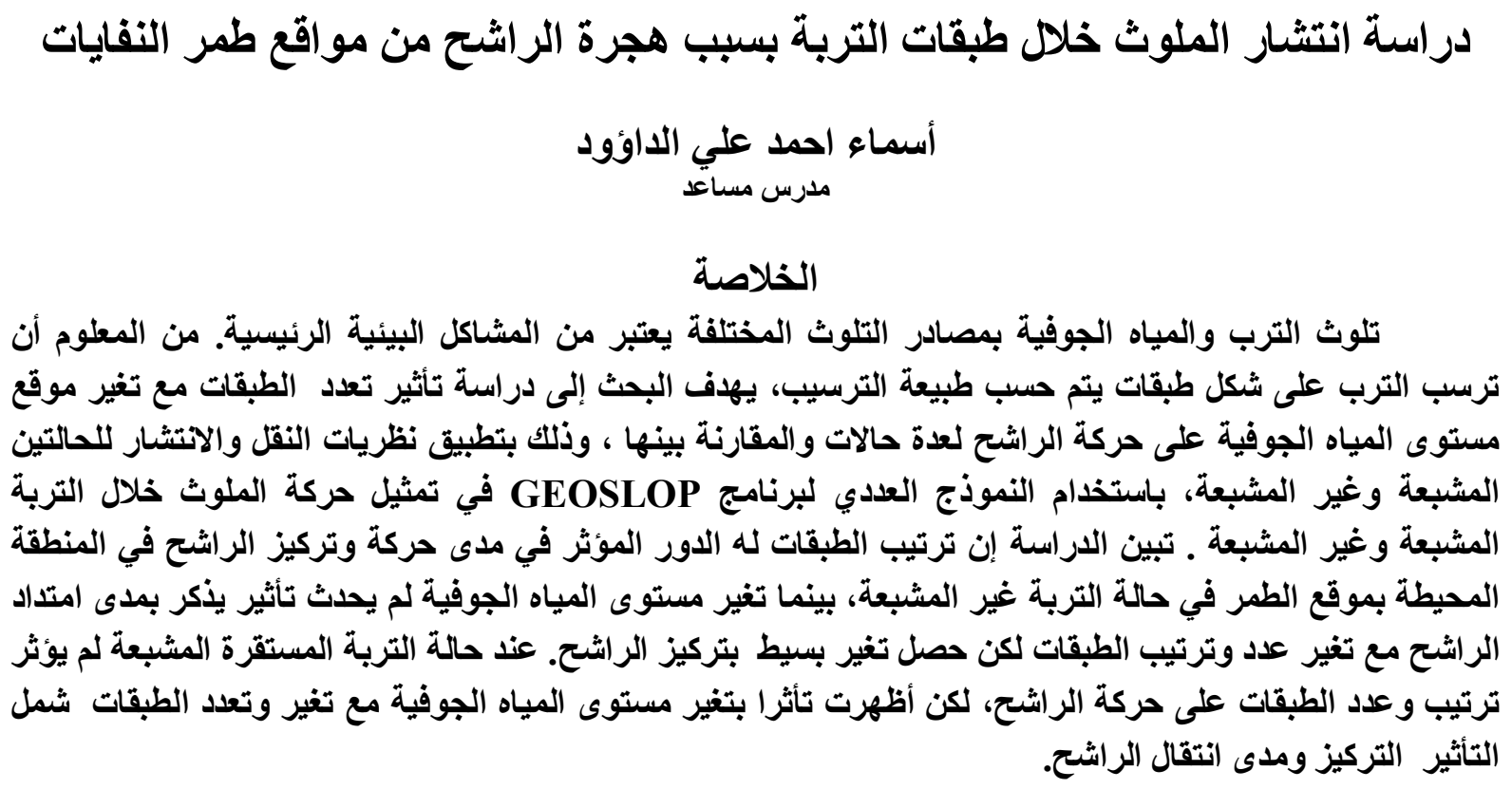




\section{Introduction}

Contamination of soil and groundwater by contaminants resulted from landfill solid wastes at a landfill sites is considered a very serious problem. In the recent years, these sites in the civilized cities were run by the relevant authorities to ensure the full control on the appropriate standards for sanitary landfill. To do so, environmental engineers utilized numerical models which simulate the landfill sites to get a preview of the contaminant movement, by simulating, mathematically, the movement of the contaminant through consecutive periods. A theoretical study tackled the movement of the contaminant through one layer in two samples of saturated and unsaturated soils, and comparing the results by utilizing equations of movement, dispersion and advection. The study concluded that the increase in moisture content with depth results in dilution of the contaminant with increasing depth in the soil liner. This has the effect of increasing the concentration gradient at the top of the soil liner and proportionally increasing the rate of diffusive mass transfer though the soil liner. Also, The advective contaminant mass flux through the soil liner is not influenced by the degree of saturation if the Darcy velocity through the soil is constant. [1].

Another theoretical study utilized numerical modeling program in simulating unhealthy landfill site in Mosul. The study concluded that an area of about $176400 \mathrm{~m}^{2}$ surrounding the landfill site could be polluted with non-volatile nitrate within 25 years, and that the contaminant reached the groundwater level after 10 years of landfill [2]. In the field experiments were conducted in central sand area of Wisconsin, Kung (1990a) observed that inclined, very coarse sand or clay and silt layers/lenses in a sandy vadose zone could funnel uniform unsaturated matrix flow into congregated flow paths. The congregated pathways bypassed most of the soil matrix as they moved to the groundwater[3]..

Later, Kung (1993) demonstrated through a laboratory experiments that funnel flow occurs along an inclined textural boundary if the following two conditions are both satisfied: 1) the water-entry potential of the lower, coarser soil is less negative than the air-entry potential of the upper, finer soil), and 2) infiltration rates are smaller than a certain critical rate which was exclusively determined by the saturated hydraulic conductivity of the overlain finer soil. When both of these conditions were satisfied, an inclined coarse layer embedded in medium or fine sand would behave like an impermeable wall of a funnel, i.e., water and contaminants would bypass the coarse sand layer and be congregated into column-like preferential paths [3].

The current paper aims to study the effect of the number and arrangement of the soil layers of different physical and hydraulic properties with changing groundwater level, in different seasons, on the movement of the contaminant under the landfill sites for 25 years. A transient case for saturated and unsaturated condition in order to make a preview of the contaminant movement through soils. Also, the current paper represent an extension a previous study (2) about the movement of the contaminant through saturated/unsaturated soil.

\section{Contaminant transport through unsaturated soil}

Unsaturated soil represents the general case of the soil and consisting of three major components: water, air and solid materials as well the contractile skin is the overlap between air and water several concepts have been used to explain the flow of water through an unsaturated soil. For example, water content gradient, or a matric suction gradient, or hydraulic head gradient have all been considered as driving potentials. The pressure and elevation gradients are combined to give a hydraulic head gradient as the fundamental driving potential[4]. . The contaminant movement is occurred through three processes: Transport, 
Attenuation and Diffusion. The basic contaminant transport processes is: advection and dispersion. Advection is the movement of contaminant with the flowing water. Dispersion is the apparent mixing and spreading of the contaminant within the flow system. Transport processes ware represented as a steady flow of water in a long tube filled with sand [5]. It is found that the dispersion-advection equation is the most effective method for representation of contaminant transport [1].

Contaminant transport through unsaturated soil is affected by the volumetric water content of the soil, which, in turn, has an impact on the coefficients of diffusion and dispersion. Kemper and Van Schaik (1966) [6] found a relationship indicates that the coefficient of diffusion increases as an exponential equation of the volumetric water content for practical purposes which do not depend on the concentration of salts. Generally, the molecular diffusion of salts in water is $(6.2 \mathrm{e}-5-2 \mathrm{e}-5) \mathrm{m}^{2} / \mathrm{sec}[7]$.

\section{Mechanism of Diffusion}

There are two diffusion mechanisms common to unsaturated soil behavior. the first type of diffusion involves the flow of air through the pore-water in a saturated or unsaturated soil. The second type of diffusion involves the movement of constituents through the water phase due to chemical concentration gradient or an osmotic suction gradient. The diffusion coefficient and its dependence on water content is of significance only in unsaturated flow and when the water flow rate is very low [5]. Constant diffusion of a chemical substance in a free solution can be experimentally simulated by Ficks' first law [4]

$$
J=-D_{o} \frac{\partial C}{\partial x}
$$

where: $J=$ the solute mass flux, $D o=$ the diffusion coefficient of the solute in water, $C=$ solution concentration, $x=$ the direction of transport, and $\partial C / \partial x=$ concentration gradient. The negative sign indicates that the flow is from higher concentration to the lower concentration of the solution [4].

\section{Numerical modeling}

Numerical modeling was performed using the finite element package of GEO-STUDIO. These programs can be used together to simulate steady-state or transient solute movement in a groundwater system in saturated/unsaturated soils.

Two-dimensional or three dimensional problems that are symmetrical about a vertical axis can be simulated. Generally, when analyzing the contaminants transport by CTRAN/W , previous and accurate information about SEEP/W must be available [5].

In SEEP/W, modeling of each materials (soil, landfill) are required: volumetric water content and hydraulic conductivity functions. Boundary conditions in SEEP/W can be entered as head values. While CTRAN/W solute concentration or solute flux values can be specified with data about dispersion, diffusion, adsorption and decay to specify the behavior of the material. In the cases of changing in Boundary conditions with time (Transit), the initial Boundary conditions for the case must be identified.

In this work identical two dimension mesh is used for both SEEP/W and CTRAN/W programs to simulate the studied cases. The elements in both the soil and landfill were approximately $(1 * 1 \mathrm{~m})$ length with infinite element at both right and left sides. The mesh is 48 

Al-Rafidain Engineering
Vol.19
No.4
August 2011

meters long and $(22 \mathrm{~m})$ depth. The dimensions of the landfill site are $(17 \mathrm{~m})$ long and $(6 \mathrm{~m})$ depth and is located at $(1 \mathrm{~m})$ from ground level as shown in fig. (1).

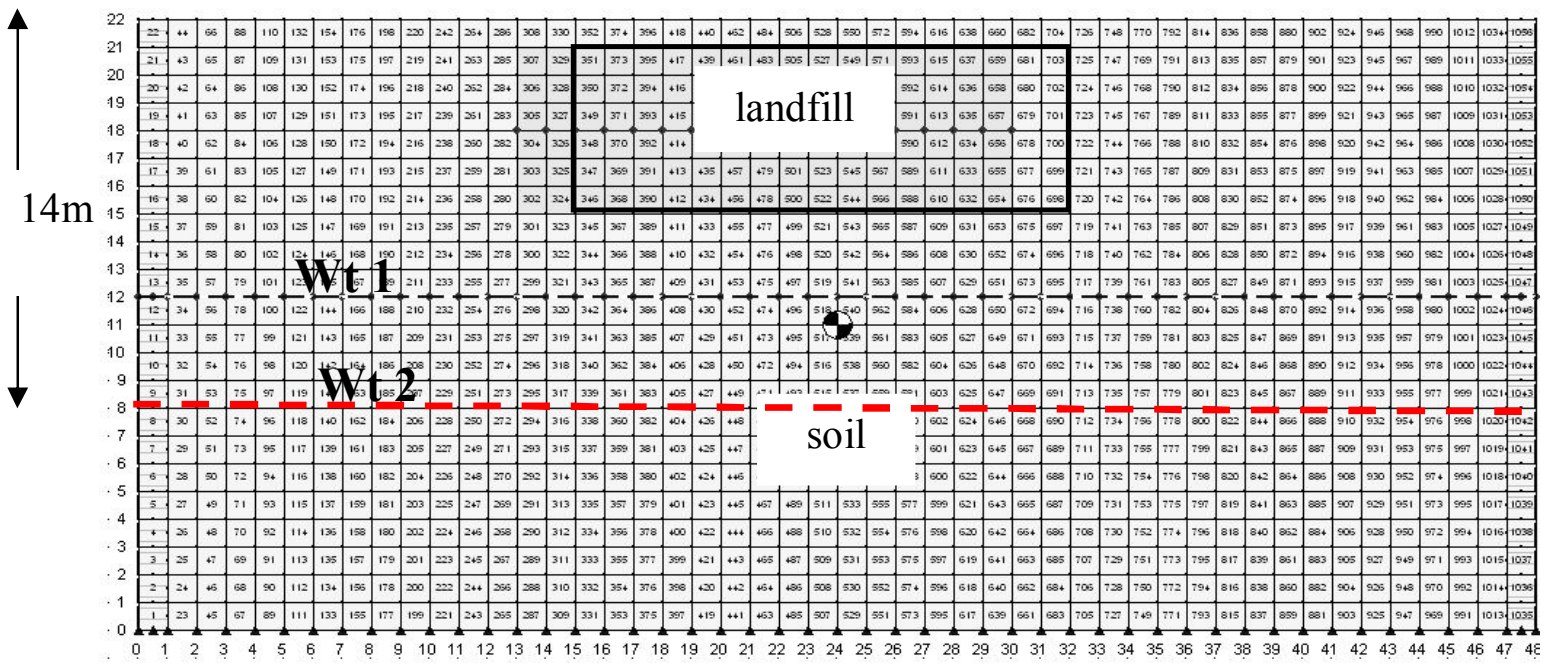

Figure (1): Finite Element Mesh of Proposes Studied Area

Concerning identifying the boundary conditions, SEEP/W, the total head $(\mathrm{H})$ which equals the elevation head of $(19 \mathrm{~m})$ is located in the middle of the landfill site, with zero flux boundary at the bottom of soil body. The groundwater level was taken to be changing in the range of (10-14) $\mathrm{m}$ in depth from the ground level as proposal. Considering the saturated and unsaturated cases for the transit case.

In the other hand, boundary condition using CTRAN/W, assumed the concentration (C) to be uniform throughout the landfill site, one type of contaminant concentration nonvolatile nitrate $(25 \mathrm{mg} / \mathrm{l})$ was chosen to be studied in this research. This concentration is one among other typical concentrations of solid waste contaminants is landfill sites, shown in table (1). The impact of adsorption and decay are neglected in the study.

Table (1): Material Concentration[s]

Typical data on the composition of leachate from new and mature landfills'

\begin{tabular}{|c|c|c|c|}
\hline \multirow[b]{3}{*}{ Constituent } & \multicolumn{3}{|c|}{ Value, $\mathrm{mg} / \mathrm{L}^{\circ}$} \\
\hline & \multicolumn{2}{|c|}{ New landfill (less than 2 years) } & \multirow{2}{*}{$\begin{array}{c}\text { Mature landfill } \\
\text { (greater than } \\
10 \text { years) }\end{array}$} \\
\hline & Range $^{c}$ & Typical ${ }^{d}$ & \\
\hline $\mathrm{BOD}_{3}$ (5-day biochemical oxygen demand) & $2,000-30,000$ & 10,000 & $100-200$ \\
\hline TOC (total organic carbon) & $1.500-20,000$ & 6,000 & $80-160$ \\
\hline COD (chemical oxygen demand) & $3.000-60,000$ & 18,000 & $100-500$ \\
\hline Total suspended solids & $200-2,000$ & 500 & $100-400$ \\
\hline Organic nitrogen & $10-800$ & 200 & $80-120$ \\
\hline Ammonia nitrogen & $10-800$ & 200 & $20-40$ \\
\hline Nitrate & $5-40$ & 25 & $5-10$ \\
\hline Total phosphorus & $5-100$ & 30 & $5-10$ \\
\hline Ortho phosphorus & $4-80$ & 20 & $4-8$ \\
\hline Alkalinity as $\mathrm{CaCO}_{3}$ & $1,000-10,000$ & 3.000 & $200-1,000$ \\
\hline $\mathrm{pH}$ & $4.5-7.5$ & 6 & $6.6-7.5$ \\
\hline Total hardness as $\mathrm{CaCO}_{3}$ & $300-10,000$ & 3,500 & $200-500$ \\
\hline Calcium & $200-3.000$ & 1.000 & $100-400$ \\
\hline Magnesium & $50-1,500$ & 250 & $50-200$ \\
\hline Potassium & $200-1,000$ & 300 & $50-400$ \\
\hline Sodium & $200-2,500$ & 500 & $100-200$ \\
\hline Chloride & $200-3,000$ & 500 & $100-400$ \\
\hline Sulfate & $50-1,000$ & 300 & $20-50$ \\
\hline Total iron & $50-1,200$ & 60 & $20-200$ \\
\hline
\end{tabular}


Three typical soils[9] ranging from silt to clay are chosen from proposed landfill sites in Mosul. The layers in these soils are arranged in variable order. These soils were selected to examine their impact on the contaminant transport within it. The properties of these types of soil are shown in table (2).

Functions that represent the permeability and the volumetric water content of the soils used in the condition of saturated and unsaturated mentioned in earlier research [2] (they have the same physical characteristics of the soils in this search). As well as the function of diffusion, the coefficient of diffusion is considered to be equal to zero in the steady saturated case because the diffusion function is effective in unsaturated soil when the speed of flow is low [5]. The distance of dispersivity $(\alpha)$ is proposed to be $2 \mathrm{~m}$ in the long direction, and $1 \mathrm{~m}$ in the perpendicular direction (The dispersivity values have units of length, such as meters or millimeters, an approximate value for dispersivity is 0.1 times the scale of the mesh geometry). Generally, the dispersion in the direction of water flow is usually higher than dispersion perpendicular to the flow direction [5].

Table (2): Soils Type [9]

\begin{tabular}{|r|c|c|c|}
\hline Soil type & Soil 1 & Soil 2 & Soil 3 \\
\hline Soil classification & CH & CL & SM \\
\hline Grain size & $\begin{array}{c}\text { sand (5\%) } \\
\text { silt }(51 \%) \\
\text { clay (44\%) }\end{array}$ & $\begin{array}{c}\text { sand }(16 \%) \\
\text { silt }(52 \%) \\
\text { clay (32\%) }\end{array}$ & $\begin{array}{c}\text { sand (66\%) } \\
\text { silt (30\%) } \\
\text { clay (4\%) }\end{array}$ \\
\hline Hydraulic conductivity (K) & $0.00001 \mathrm{E}-3$ & $0.01 \mathrm{E}-3$ & $1 \mathrm{E}-3$ \\
\hline Porosity (n) & 0.31 & 0.39 & 0.5 \\
\hline Volumetric water content $(\Theta)$ & 0.31 & 0.39 & 0.5 \\
\hline
\end{tabular}

In order to illustrate the impact of the natural formation the soil, the cases shown in table (3) are chosen, where some field geological investigations in Mosul revealed that the presented assumptions are almost represented to some places surrounding Mosul [10], [11].

Table (3) : Studied Cases for Layers Order Under The Landfill Site

\begin{tabular}{|c|c|l|l|}
\hline Cases & No. of Layers & $\begin{array}{l}\text { Layer } \\
\text { Arrangements }\end{array}$ & $\begin{array}{l}\text { Layers thickness } \\
(\mathrm{m})\end{array}$ \\
\hline 1 & One & CH & 22 \\
\hline 2 & Two & CH then SM & CH (13),SM (9) \\
\hline 3 & Two & SM then CH & SM(13), CH(9) \\
\hline 4 & Three & $\begin{array}{l}\text { SM between two } \\
\text { layer of CH }\end{array}$ & SM(6), CH (8) \\
\hline 5 & Three & $\begin{array}{l}\text { SM then CL and } \\
\text { CH }\end{array}$ & $\begin{array}{l}\text { CH(7), CL(7), } \\
\text { SM (8) }\end{array}$ \\
\hline
\end{tabular}



Al-Rafidain Engineering
Vol.19
No.4
August 2011

\section{Result \&Discussion}

The effects of the order of layers on the movement of the nitrate, are shown in figures $(2,3,4,5$, and 6$)$. These figures show the description of the numerical model (case a), the movement of the contaminant (case b), and the relationship between the concentration and the movement of the contaminant (case c), respectively for each case (for unsaturated soil). The concentration of contaminant reached a distance of $(7,15,3,6,2) \mathrm{m}$ for cases $(1,2,3,4,5)$ respectively under the landfill site .
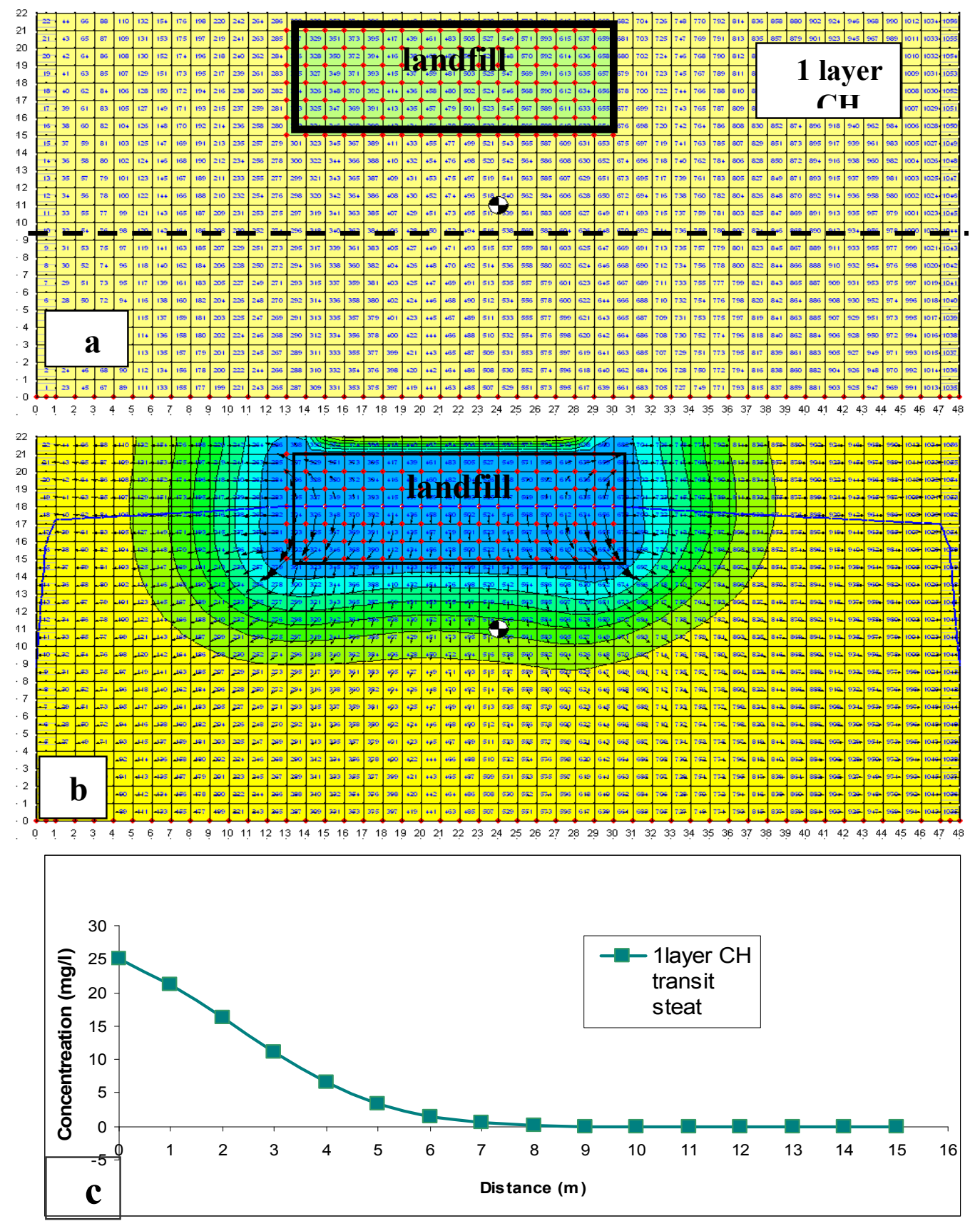

Fig.(2) (a): Description of Numerical Model for Case 1.

(b): Contaminant Transport.

(c): The Relationship between Concentration and Contaminant Transport. 
These distances are represented by the contour lines in the mentioned figures. It is worth noting that in the cases 3 and 5, the direction of the movement of the contaminant (represented by the direction of the arrows) is toward the landfill site. This means that the clay layer here serves as a lining of the landfill site, while in case 4 the movement of the contaminant is toward the silt layer taking the direction of the arrow where the contaminant moved 6 meters only, and the contour lines never reached the clay layer. On the other hand, the relationship between the concentrations of the contaminant with its movement shows a gradual decline in the concentration of the contaminant at a different rate
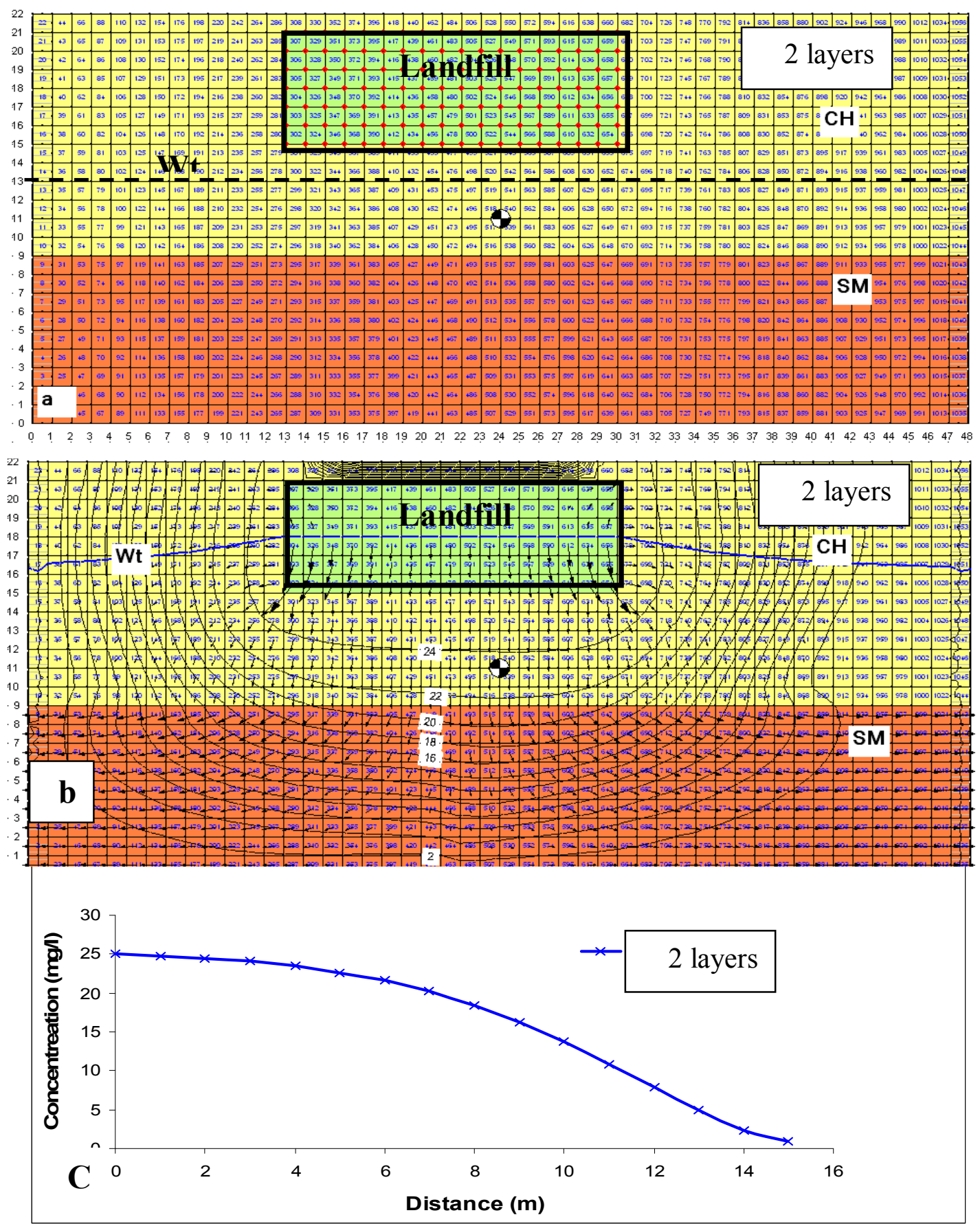

Fig.(3) (a): Description of Numerical Model for Case2.

(b): Contaminant Transport.

(c): The Relationship between Concentration and Contaminant Transport. 

Al-Rafidain Engineering
Vol.19
No.4
August 2011

of $(20 \%, 8 \%, 44 \%, 30 \%, 80 \%)$ per meter respectively for all studied cases, when the contaminant extended below the landfill level.

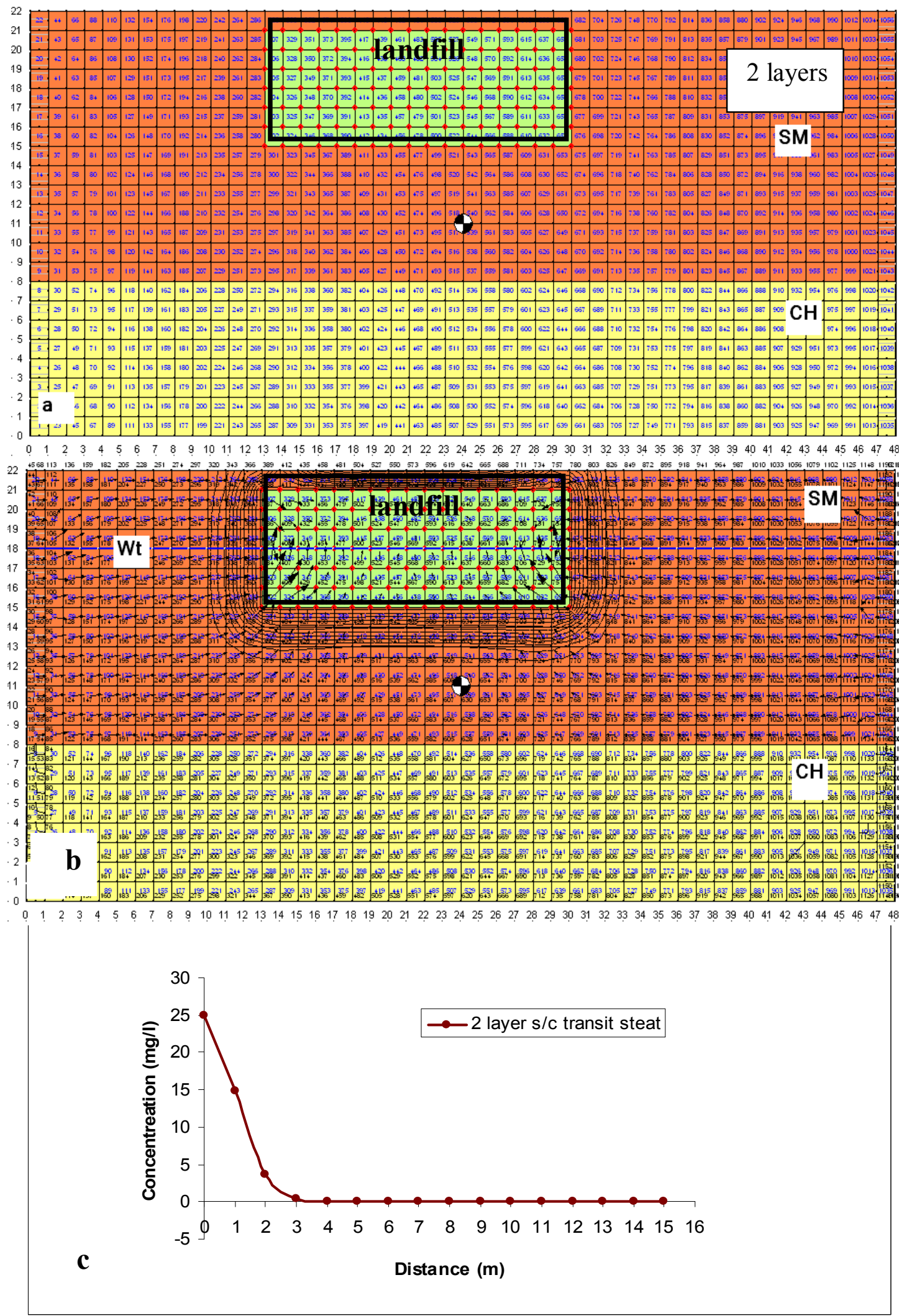

Fig.(4) (a): Description of Numerical Model for Case3.

(b): Contaminant Transport.

(c): The Relationship between Concentration and Contaminant Transport. 
Velocity variation may occur at the microscopic level due to the friction between the soil particles and the fluid and also due to the curvatures in the flow path. these velocity variation result in concentration variation, the contamination appears to have dispersed[5].

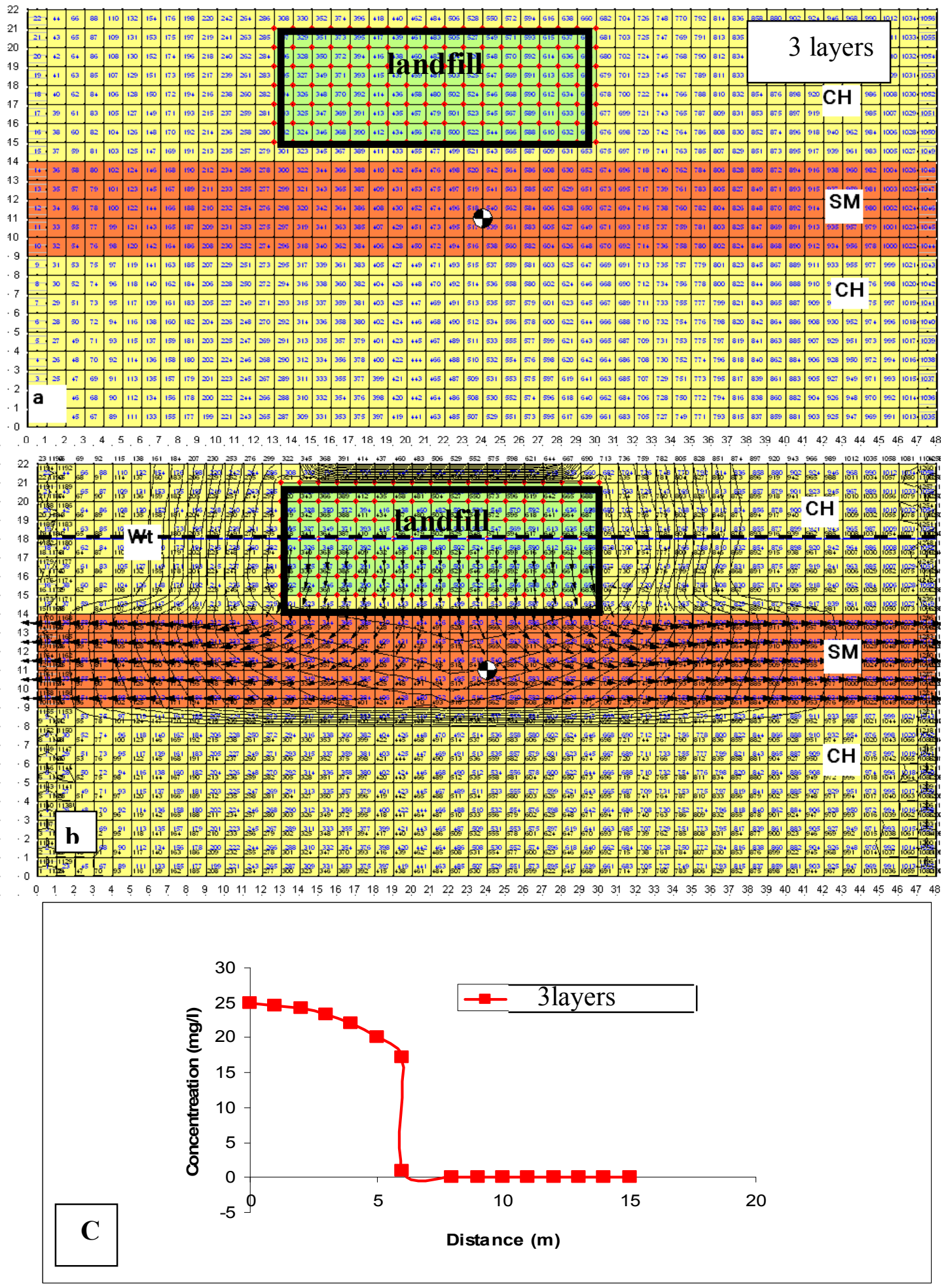

Fig.(5) (a): Description of Numerical Model for Case 4.

(b): Contaminant Transport.

(c): The Relationship between Concentration and Contaminant Transport 

Al-Rafidain Engineering
Vol.19
No.4
August 2011

In addition partial saturation of the soil liner leads to a reduction in cross-sectional area available for contaminant mass transport, which has the effect of decreasing the diffusive mass flux[1].This is associated with the process of the migration and movement of the contaminant from a constant resource under the effect of the two movement methods mentioned in [5]. It has been noticed in case 4 that a sudden change in the curve had occurred at a distance of 6 meters below the landfill level, so that the value of concentration is reaches approximately zero. Also, it has been found that the decrement rate in the concentration of the contaminant at 5-6 meters depth is $77 \%$.

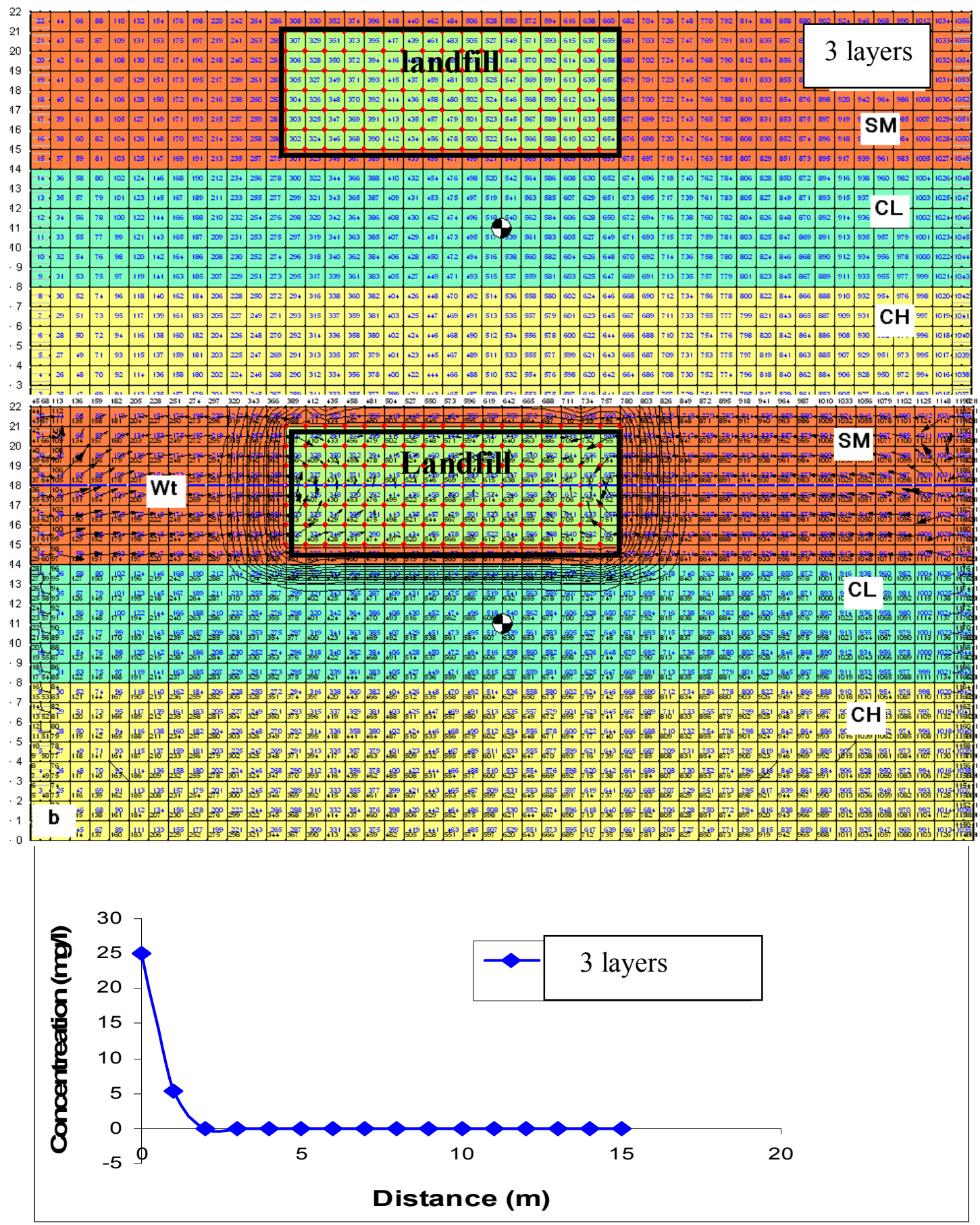

Fig.(6)(a): Description of Numerical Model for Case 5.

(b): Contaminant Transport.

(c): The Relationship between Concentration and Contaminant Transport. 
Comparing the studied cases ( 1 to 5) shown in fig.(7), revealed that the order of layers, and not the number of layers has the major impact on the concentration and the movement of the contaminant through the area surrounding the landfill site. Fig.(7) also shows that when a silt layer is located under the clay layer (case 2) the rate of the movement of the contaminant is faster than other case $s$, extend almost greater distance in which the order of the layers is different. Also it is noticed that the concentration of the contaminant decreases constantly with the distance from the source of pollution. When a silt layer is located in the middle of a clay layer (case 4), the contaminant is banned from movement downwards but is allowed to move through the same layer as deducted from the sudden change in the shape of the curve. This coincides with the results of Kung (1993) [3] about using a layer of fine or coarse soil as an impermeable wall. In addition, an increase in the rate of concentration decline due to the movement of the contaminant is found to be doubled, when the order of the layers is accompanied with the reduction of permeability (from top to bottom). This is evident when there is a single clay layer $\mathrm{CH}$ as compared to the case of double layers (silt layer over a clay layer $\mathrm{CH}$ ) and triple layers (silt layer SM over two clay layers $\mathrm{CL}, \mathrm{CH}$ ), because these layers could serve as a filter.

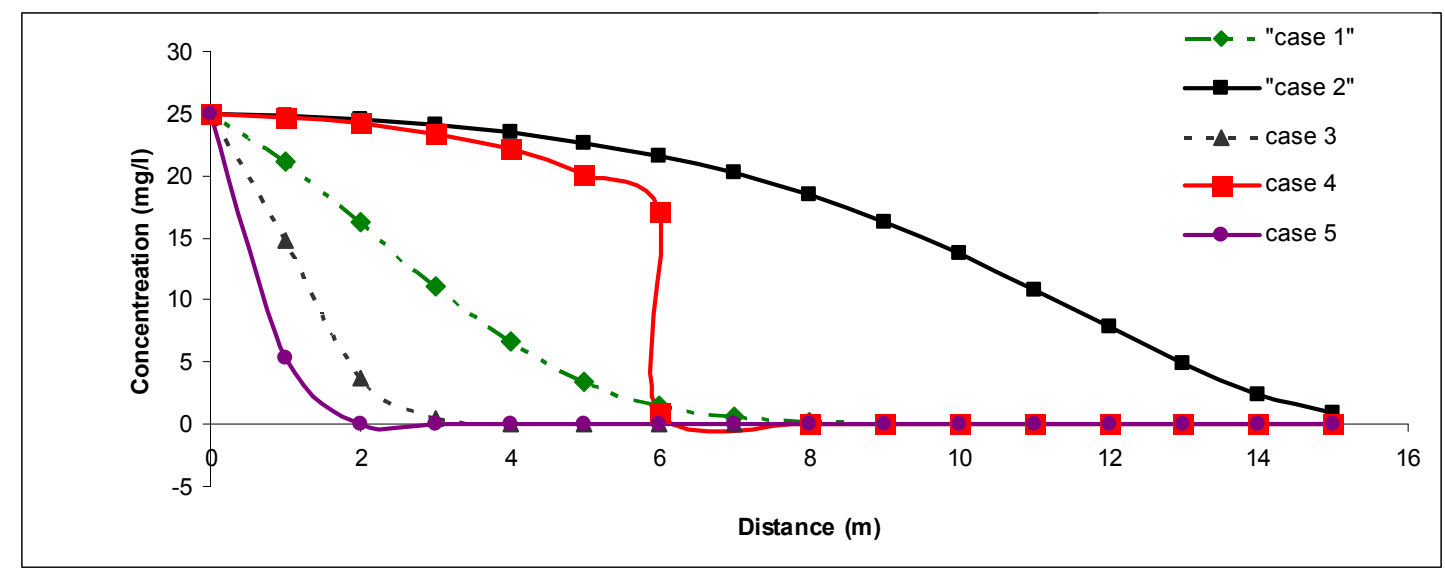

Fig.(7). The relationship between the concentration of the contaminant and its transition beneath the dumping site for studded cases.

The previous results concern the transient flow (case) of an unsaturated soil as compared to the steady saturated soil as shown in fig.(8). In this figure, there is an obvious match between the curves related to the saturated state for all the cases dealt with the order and multiplicity of layers. The contaminant was observed to extend to 3 meters below the landfill site recording the highest concentration at the groundwater level for the saturated state. This concentration declines gradually due to the process of dilution caused by the groundwater. Whereas for the transient unsaturated state, there was a difference between the ranges of contaminant movement with the order and multiplicity of layers as mentioned previously. This difference in the ranges of contaminant movement is attributed to the possibility of fast contaminant movement through the connected paths in the unsaturated soil[1], but in the same time, the curves show that the concentration of the contaminant when movement through the saturated state is higher than the unsaturated state. This could be attributed to increasing the water content with the depth that leads to diluting the concentration. This give the meaning that the concentration of the contaminant is higher in 
the upper layers, which coincides with the relationship between the diffusion and the volumetric water content, this coincides with the results of the Fityus 1999 [1].

Fall in ground water level (for example from $10 \mathrm{~m}$ to $14 \mathrm{~m}$ ) showed an impact on the contaminant movement with the order and multiplicity of layers for both the saturated and unsaturated cases. Fig.(9) illustrates the relationship between the concentration and the contamination movement after changing the groundwater level for the transient unsaturated case. In the other hand no change in the contaminant movement with changing the order and number of layers was recorded, but there was a small reduction in the concentration of the contaminant, in the range of $4-20 \%$ when changing the groundwater level. This change was recorded when the silt layer was under the clay layer (case 2) and this case showed the highest ratio compared to the other cases.

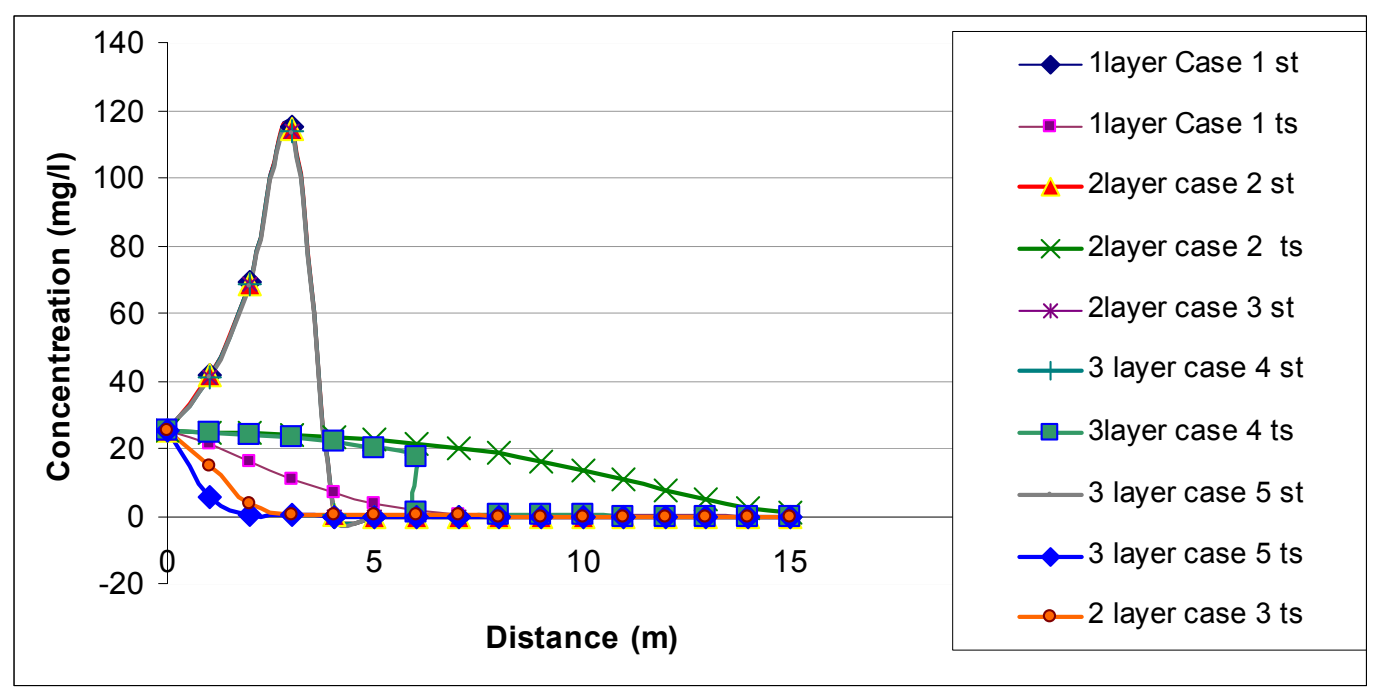

Fig.(8). The relationship between the concentration of the contaminant and its transition beneath the landfill site for the standard cases of in both saturated and unsaturated soils (st steady $\&$ ts transit state).

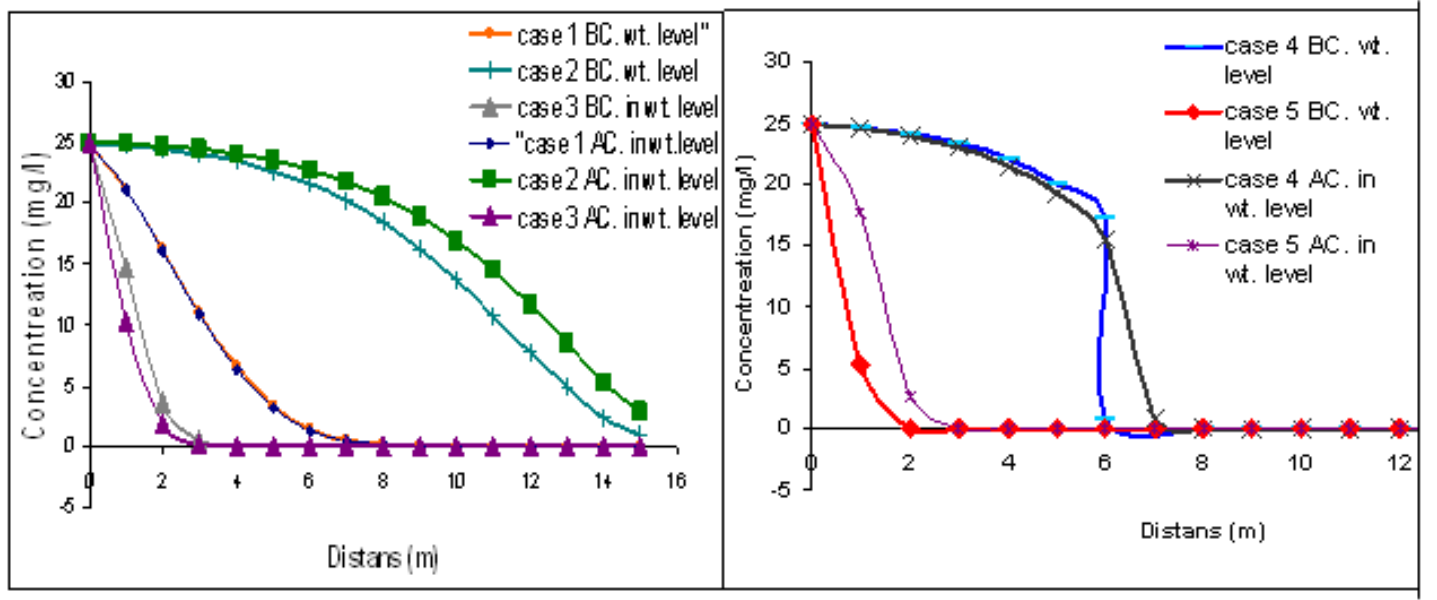

Fig.(9) Contaminant transition through multi-layer transient soil when changing the groundwater level from $10 \mathrm{~m}$ to $14 \mathrm{~m}($ $\mathrm{BC}, \mathrm{AC}$ represent before \& after change). 
The steady saturated case showed a significant change in the concentration and the movement of the contaminant due to changing the groundwater level as shown in fig.(10). The contaminant moved 7 meters under the landfill site with changing the order and number of layers. This distance can be attributed to the change in pressure with the change in the groundwater level. Also, changing the groundwater level for the saturated case was accompanied with an increment in concentration with changing the order and number of layers. This increments were $(40 \%$, $60 \%, 67 \%, 90 \%)$ for the $2^{\text {nd }}, 1^{\text {st }}, 3^{\text {rd }}$ and $5^{\text {th }}$ cases respectively. The reason behind this difference can be attributed to the hydraulic difference (permeability and porosity) for each layer because each layer is assembled along different ages. The diagrams also reveal that when the silt layer was located in the middle of a clay layer $\mathrm{CH}$ (case 4), there was a reduction in the concentration of the contaminant if compared to the original groundwater level. This reduction may result from lowering the groundwater level under the silt layer which means that the total section area which allows the movement of the contaminant is small which consequently reduces the diffusion of the contaminant[1].
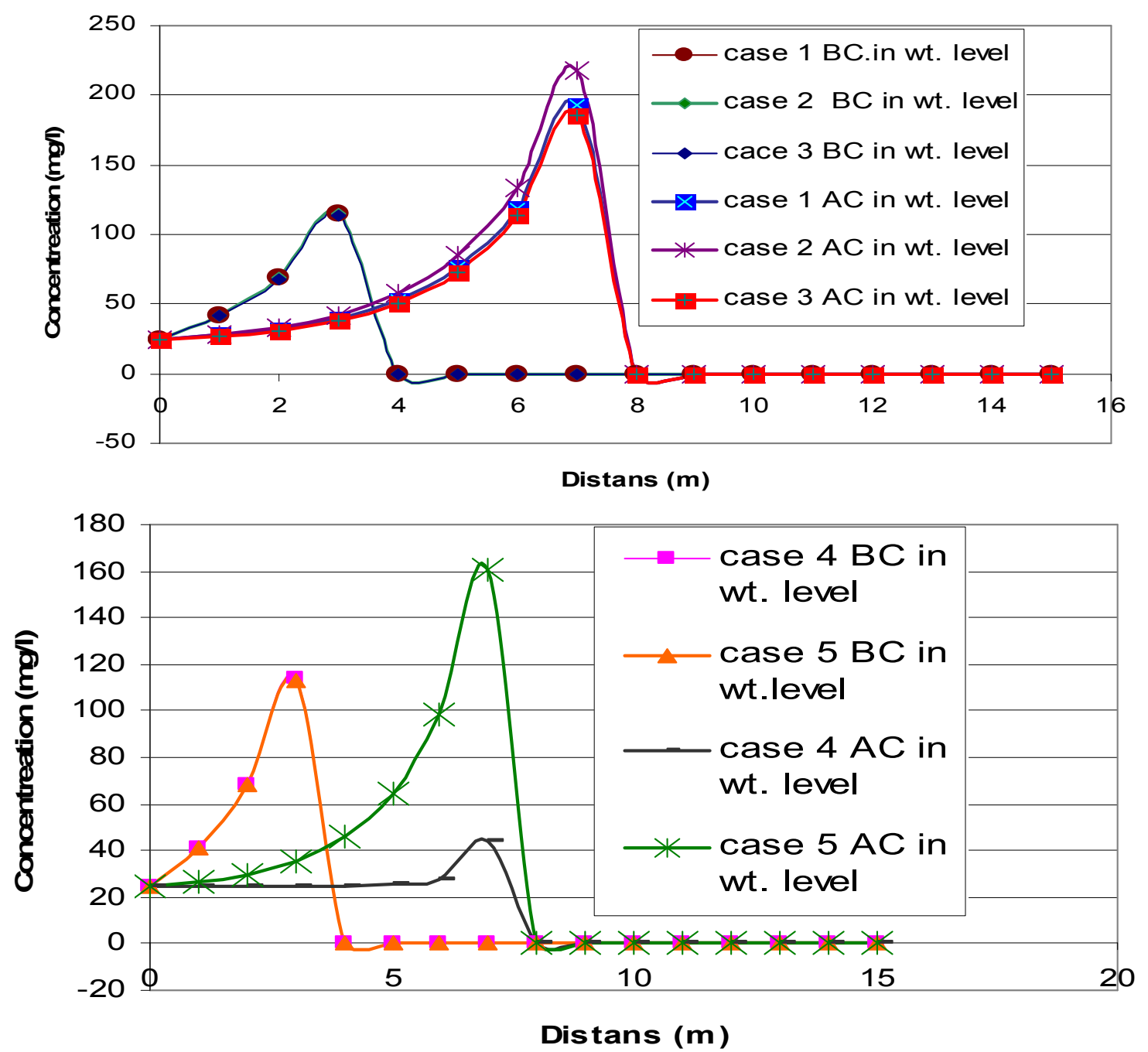

Fig.(10) Contaminant transition through multi-layer steady stead soil when changing the groundwater level from $10 \mathrm{~m}$ to $14 \mathrm{~m}$ ( BC,AC represent Before \& After Change). 


\section{Conclusions}

1- the results revealed that the arrangement of layers and not the number of layers, has a major impact on the concentration and movement of the contaminant in the area surrounding the dumping site in case of the transient unsaturated soil. Whereas the arrangement and number of layers had no impact on the movement of the contaminant in the case of saturated soil.

2- A silt layer, when located between two clay layers, facilitates the movement of contaminant through this layer. Hence, limits and inhibits the movement of the contaminant downwards.

3- The order of the placement of lining layers under a dumping site is found to be a function of permeability of the layer. When the permeability decreases, a reduction in the concentration of the contaminant movement through the layers from top to bottom was occurred in transient stead.

4- The approaches of leachate to ground water level with the depth leads to diluting the concentration of the contaminant. A values ranging from ( 8 to 80$) \%$ for each meter were found. This causes an increasing in the concentration of the contaminant at the upper layers with a values proportional to the relationship between the diffusion and depth.

5- The reduction in the groundwater level in the transient unsaturated case had no impact on the movement of the contaminant with the variation of the number and order of layers. Nevertheless, there was a small change in the concentration of the contaminant ranged between ( 4 and 20 )\% for the five studied cases. In the other hand, changing the number and order of layers of the steady saturated soil was found to be affected by the fluctuation of the groundwater level. This effect included the concentration and movement of the contaminant

\section{REFERENCES}

1. S.G. Fityus, D.W. Smith, and J.R. Booker,(1999), " Contaminant transport through an unsaturated soil liner beneath a landfill" Can. Geotech. J. 36: 330-354.

2. Khattab,S.A.A,AL-Daood,A.A,Kalil,A.A(2010)" Range of Contaminant Transport in Soil Under Saturated/ Unsaturated Conditions With Case Study "AlRafidain.Engineering Journal,vol.18,no.2, university of Mosul .

3. K-J.S. Kung(2009),"Funnel-Type flow and Its impact on Contaminant transport in unsaturated soil",SSWMP Publication \#4.39

4. Fredlun, D. G. and Rahardjo, H., (1993), "Soil Mechanics For Unsaturated Soils", John Witey \& Son, In,lost addition, USA.

5. GEO-SLOP User's Guid, (2002), "GEO-SLOPE OFFICE For Finite Element Analysis", Ver. 5.

6. Kemper, W.D., and Van Shaik, J. C., (1966), Diffusion of salts in Clay-Water Systems, Soil Science of America proceedings, Vol.30.

7. Jor G., (1977), "international Society for Ecological Tetra Tech Inc. "Handbook of Environmental Date and Ecological Parameters".

8. "Solid-Waste Management", Mc Graw-Hill International Editions Civil Engineering Senses.

9. AL-Omary, A. M. A., (2007), "Effect of Soil Type \& Compaction Condition on Behavior of Soil-Water Characteristic Curve for Soil Selected From Mosul", un published M Sc. Thesis, Civil Engineering department, University of Mosul, 
10. AL- Layla, M.T.,Thabet, K.M,(1990),"Formation of cavities in the alluvial deposit in Mosul city"the second scientific conference of SDRC. Mosul University -MosulIraq, 18-20-March 1990.

11. AL-ANE,J.M,Ahmed ,M.M,(1990),"Evaluation of subsurface sediments in AL-Area using vertical electrical sounding ", the second scientific conference of SDRC. Mosul University -Mosul- Iraq,18-20-March 1990. 